\title{
El ritual de la Apertura de la Boca en la tumba de Djehuty (TT 11)
}

\author{
Jose M. SERRANO DELGADO
}

La liturgia de la Apertura de la boca en la tumba de Djehuty (TT 11) esta relativamente bien conservada. Se sitúa, como es habitual, en el pasillo que conduce a la capilla interna. El presente trabajo en un informe preliminar en el que destacamos el estado muy completo de la copia, posiblemente una de las más antiguas documentadas, lo que significa una importante contribución a la mejor comprensión de este ritual funerario en su conjunto.

\section{The ritual of the Opening of the Mouth in the tomb of Djehuty (TT 11)}

The liturgy of the Opening of the Mouth represented in the tomb of Djehuty (TT 11) is relatively well preserved. It is placed, as is customary, in the corridor leading to the inner chapel. The present paper is a preliminary report, drawing attention to the fact that here we have a very complete copy of this funerary ritual, and probably one of the oldest preserved, therefore signifying a very important contribution to the better understanding of the whole ceremony.

KEY wORDs: Thebes, TT 11, 18th Dynasty, Ritual of the Opening of the Mouth

\section{L} a Apertura de la Boca, como es bien sabido, es uno de los componentes fundamentales de la liturgia funeraria en la época Faraónica. Se trata de un ritual de resurrección, renacimiento y revitalización de la imagen (estatua) o del cuerpo momificado. Su eficacia es especialmente relevante para dotar al difunto de la capacidad de recibir con aprovechamiento las ofrendas que se le deben y para que en definitiva sea capaz de alimentarse y nutrirse de ellas. La Apertura de la Boca ha sido objeto de atención y de interés por parte de los estu- diosos desde época muy temprana, razón por la cual contamos con buenas síntesis o trabajos de conjunto, siendo la clásica presentación de E. Otto la más destacada y conocida, referente aún indiscutible pese a los años transcurridos desde su publicación ${ }^{1}$. Conviene no obstante tener en cuenta que esta obra se apoya fundamentalmente en un corpus de siete copias del ritual, de las cuales tan solo una (la que figura en la TT 100, de Rejmira) corresponde a la Dinastía XVIII, el período que enfoca nuestro estudio ${ }^{2}$. Esto significa que la gran mayoría de los documentos

1. Otto, 1960. Ver tambien, Baly, 1930; Barthelmess, 1992: 93 y ss.; Schulman, 1984; Assmann, 2003a: 53-60; 2003b: 456 y ss.; Roth, 1992: 113-147; Roth, 1993: 57-79; Fischer-Elfert, 1998.

2. Además de la ya citada versión de Rejmira, las otras seis son: las tumba de Sethy I y de Tausret en el Valle de los Reyes (KV 17 y KV 14 respectivamente), el sarcófago de Butejamón (en Turín), la capilla de Amenirdis en Medinet Habu, la tumba de Padimenope (TT 53), y un papiro de época Grecorromana (Otto, 1960: 175 y ss.).

Fecha de recepción: 17 de enero de 2007

Fecha de aceptación: 25 de junio de 2007 
pertinentes a la Apertura de la Boca se encuentren aún hoy día sin publicar o sin valorar científicamente, lo que hace patente la necesidad de estudios monográficos y presentaciones de detalle de las diferentes versiones conservadas.

La presente aportación se encuadra dentro en los trabajos y actuaciones con los que el Proyecto Djehuty enfoca la puesta en valor de las Tumbas Tebanas 11 y 12 y su entorno arqueológico y, más específicamente, la atención que merecen sus relieves e inscripciones. Dentro del programa iconográfico y textual de la tumba de Djehuty (TT 11), en lo que a nuestro modo de ver sería un plan orgánicamente pensado de las representaciones sagradas, la ceremonia de la Apertura de la Boca ocupa un lugar destacado ${ }^{3}$. La encontramos en el sitio que comúnmente le corresponde según la práctica habitual durante la Dinastía XVIII ${ }^{4}$, es decir, en la pared derecha del pasillo o corredor que conduce hasta la sección más interna de la tumba, pared que ocupa en gran parte, quedando el resto del espacio, como también es la norma, para la escena de la caza en el desierto, que ocupa el sector más externo de dicho corredor.

El panel en cuestión se encuentra en un estado de conservación que no podemos calificar de bueno. A primera vista se aprecian claramente huecos y roturas que han dejado una secuela importante de mutilaciones en las escenas y los textos que las acompañan. Muchos de estos daños provienen sin duda de destrucciones y saqueos antiguos; de ahí la notable cantidad de fragmentos, algunos - para nuestra fortuna- de considerable tamaño y en buen estado, que se han encontrado en las excavaciones del exterior, en especial en el patio de la TT 11. Otros son más recientes, relacionados quizás con el expolio de las tumbas tebanas con vista al tráfico de antigüedades, como muestran algunos huecos sospechosamente regulares en la pared, e incluso la huella del trabajo de la sierra durante algunos empeños de expolio que quedaron sin concluir. Para que nos hagamos una idea más precisa, la excavación del patio de Djehuty ha permitido recuperar más de cincuenta fragmentos epigráficos correspondientes a la Apertura de la $\mathrm{Boca}^{5}$. En algunos casos han servido par reconstruir importantes secuencias del ritual, como los tres fragmentos de la Escena 47 (que casan entre sí) y que ofrecen unas once líneas de texto muy bien conservados y claramente legibles.

Por otra parte, la pared ha llegado hasta nosotros bastante sucia, cubierta de costras y concreciones que habrá que retirar con mucho cuidado cuando se acometa la restauración integral del interior de la tumba. Además, como sucede en otros lugares en la TT 11, parte de este panel se ha visto afectado por un proceso de erosión o de deterioro de la piedra que, por decirlo de alguna manera, ha atenuado el volumen de los relieves y los textos, desdibujándolos y desvaneciéndolos en mayor o menor medida, dejando una impresión general de "lavado", y dificultando en cualquier caso su lectura, su reconstrucción y estudio. Quizás por estas razones, aun conociéndose la existencia de esta versión de la Apertura de la Boca desde hace más de un siglo ${ }^{6}$, no ha sido tomada en consideración, ni se ha aprovechado realmente

3. Para el desarrollo del Proyecto Djehuty, sus diferentes campañas y objetivos, ver: Galán, 2006; y el sitio web: www. excavacioenegipto.com.

4. Engelmann-von Carnap, 1999: 150-1 y 228-230.

5. Gracias al meticuloso y ordenado trabajo de uno de los epigrafistas del proyecto Djehuty, Andrés Diego Espinel (Instituto de Filología, CSIC-Madrid) han podido identificarse la mayoría de estos fragmentos.

6. En realidad, desde la excavación que llevaron a cabo Spiegelberg y Newberry por cuenta del Marqués de Northampton (Northampton, Spiegelberg y Newberry, 1908). 
para un mejor conocimiento de este ritual ${ }^{7}$. La intención de este informe preliminar es, por el contrario, poner de relieve las potencialidades de su estudio, y las aportaciones que, ya desde una primera y parcial aproximación puramente descriptiva, puede ofrecer.

\section{Distribución de escenas}

El panel tiene una ordenación general que lo articula aproximadamente en dos registros (fig. 1):

1) Uno superior, más ancho, denso y abigarrado en cuanto a las representaciones que ofrece, incluso con escenas superpuestas o yuxtaposiciones de varios textos dentro de un mismo registro.

2) Otro inferior, más estrecho y de desarrollo lineal, que se centra, como vamos a ver, en las fases finales del ritual. Hay que tener presente que este registro ha sufrido más el paso del tiempo y que incluso aún quedan fragmentos de los textos correspondientes cubiertos por los escombros procedentes de la capilla que todavía no han sido retirados del pasillo.

La orientación es la habitual, de derecha a izquierda según miramos hacia la pared, de manera que el desarrollo de la liturgia apunta hacia la parte más profunda del sepulcro. A diferencia de lo que pasa en otras tumbas -especialmente en Rejmira (TT 100), que suele tomarse como el modelo o paradigma-, la lectura de las escenas se hace de arriba hacia abajo. La figura objeto de la liturgia es, no ya la estatua del difunto (como, según algunos, correspondía en el origen de este ritual, y tal como aparece en la citada TT 100) sino la momia, lo que es la tónica dominante en la representaciones desde la Dinastía XVIII en adelante $^{8}$. Casi todo el texto aparece en columnas ${ }^{9}$, presentando los signos orientados en el sentido inverso al de su lectura, en escritura retrógada, algo no demasiado extraño, pero que no deja de ser otro detalle más de un cierto tratamiento especial de los textos que parece una marca de identidad en la tumba de Djehuty ${ }^{10}$.

Vamos a ver cómo se articula la distribución de escenas.

A) El registro superior comienza, hacia el extremo derecho, con la formula que inaugura todo el ritual (Escena 1) ${ }^{11}$, y que se ha preservado con mucha fortuna, ya que esta sección de la pared es una de las que mas deteriorada aparece. A continuación se representan las actividades iniciales o preparatorias (Escenas 2-7), que consisten en esencia en purificaciones realizadas respectivamente con agua, con natrón y con incienso, por este orden. Cada una de estas purificaciones se ejecuta por duplicado, siguiendo un modelo litúrgico dual que es típicamente egipcio: así, por ejemplo, en la Escena 4 se usa

7. Un buen exponente de ello es el escueto comentario de Otto (1960: vol. II, 174): “Ursprünglich ausführliche Ritualdarstellung mit Sarkofag als Objekt an der rechten Wand des Längsraumes des Grabes. Text und Darstellungen stark zerstört". Hasta la fecha no se ha publicado ni una sola línea o imagen de este interesante documento.

8. Barthelmess, 1992: 93-100. Como vamos a ver más abajo, este dato va a tener relevancia en cuanto a la forma en que aparece reconstruido el ritual en la tumba de Djehuty.

9. A excepción de algunos que, como cartelas o bocadillos, acompañan a las figuras y oficiantes que suponen la expresión iconográfica del ritual.

10. Ver por ejemplo, los textos criptográficos en la decoración exterior de la tumba, o la peculiar ordenación de las líneas en la célebre estela autobiográfica. $C f$. Andrés Diego Espinel, en el primer volumen de las actas de este congreso, y A. de Diego Provencio, 2003: 117 y ss.

11. Irt wp-r $n$ [d $\underline{d}$ wty]": "Haciendo la Apertura de la Boca de [Djehuty]” (Otto, 1960: vol. II, 34-37). 


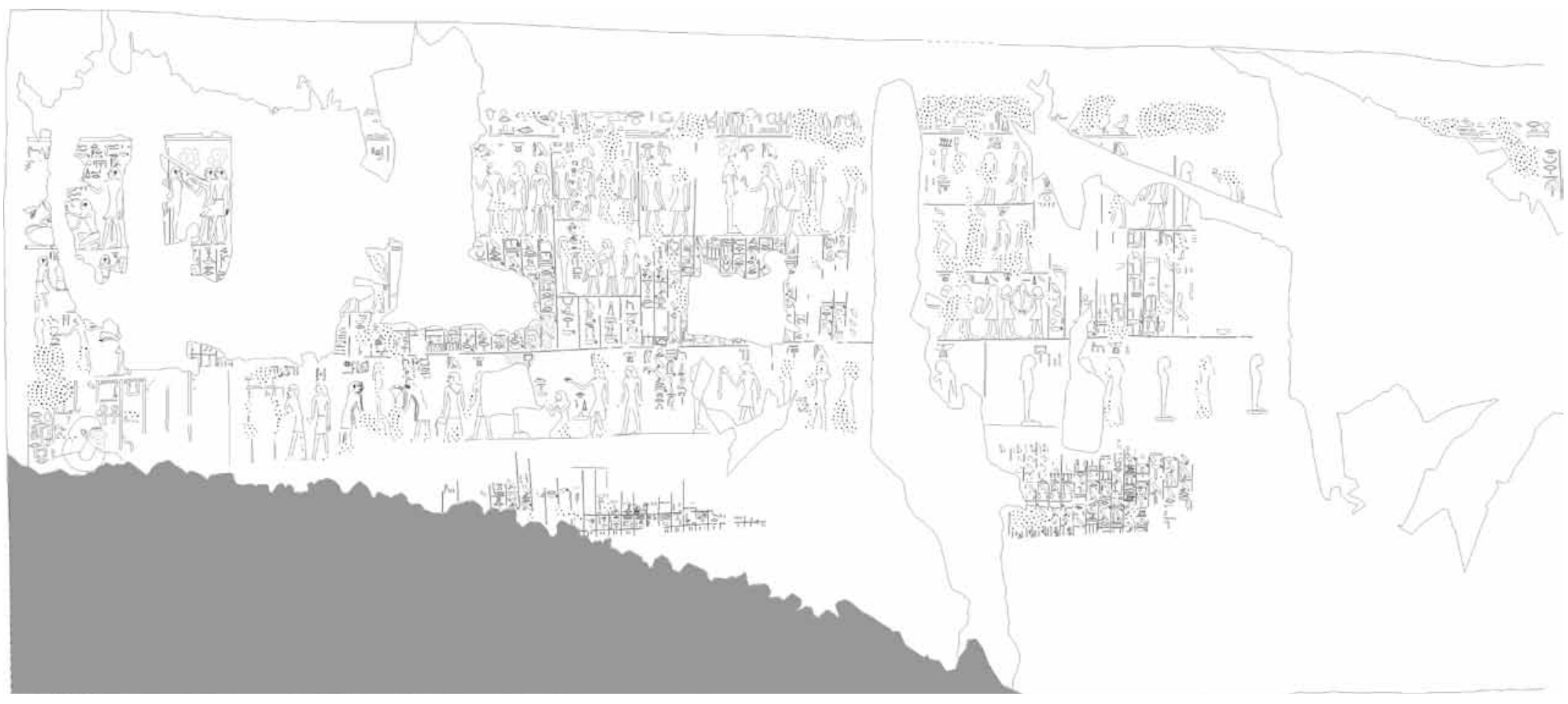

Figura 1. Panel completo de la Apertura de la Boca en la TT 11 
natrón del Alto Egipto, y en la siguiente, la 5, natrón del Bajo Egipto ${ }^{12}$.

El resto de este registro superior, con más de 15 Escenas o pasajes identificados, está dedicado de forma específica a lo que propiamente dicho es la Apertura de la Boca, con la intervención de distintos sacerdote $\mathrm{u}$ oficiantes ( $\mathrm{sm}$, $r-p^{c}, s 3-m r=f$, $h r y-h b t$, etc.) y con el concurso de diferentes objetos, utensilios o herramientas sagradas que, por turno, se aplican o se acercan al rostro del difunto ( $w r-h k^{3} 3 w, p s s ̌-k f, n t r w y$, etc. $)^{13}$. Hay dos detalles sobre los que no queremos dejar de llamar la atención en esta parte de la representación del ritual.

Por un lado, da la impresión de que se hace un énfasis especial en las escenas del sacrificio del bóvido, en su despiece o mutilación, y en el acto consiguiente de presentar la pata delantera y el corazón del animal a la momia. De nuevo nos encontramos con un pasaje ritual que se repite. Se trata de las Escenas 23-25 y 43-44. Para muchos estudiosos, se trata del momento fundamental de esta liturgia, que no tiene que ver nada con una ofrenda al difunto, como pensaba, entre otros, $\mathrm{Otto}^{14}$, sino que realmente supone escenificar de forma concreta la acción de Apertura de la Boca. La pata del toro asume la función del instrumento sagrado preceptivo, similar en muchos sentidos a la célebre azuela que comúnmente asociamos a este ritual ${ }^{15}$. Sea como fuere, la versión de la tumba de Djehuty le asigna sin duda una especial relevancia, desarrollando iconográficamente con gran fuerza expresiva y lujo de detalles estas dramáticas escenas. Además, dentro de lo que es la arquitectura de la tumba, no aparecen en un lugar cualquiera, sino que se sitúan en el emplazamiento religiosamente quizás más significativo y privilegiado de este registro superior, en el extremo izquierdo, la parte más profunda, pegada a la pared que separa de la capilla interna o sancta sanctorum de la TT $11^{16}$.

El otro elemento que queríamos destacar es la ausencia de un amplio grupo de pasajes de la Apertura de la Boca que se supone deberían haber aparecido en este registro. Concretamente nos referimos a la secuencia de Escenas 8 a 21 (siempre según la numeración de Otto y su reconstrucción canónica del ritual), que constituyen una importante sección de la liturgia, tal y como demuestra, por ejemplo, el notable lugar que ocupa en la tumba de Rejmira. En Djehuty, solo aparecen las Escenas 9 y 11/19 (ambas con dudas), que conciernen a cambios de atuendo del sacerdote $\mathrm{sm}$. Veamos mas en detalle de que se trata: de nuevo nos encontramos con una especie de representación teatral o drama sacro que ofrece coherencia interna y unidad de desarrollo; la acción se sitúa en lo que Otto ha dado en llamar el "taller de los artesanos" (la "mansión de oro" - ht nbw). Allí tiene lugar la dormición del sacerdote $s m^{17}$, que posiblemente a través de un trance mágico-religioso análogo a la incubatio

12. Cf. Otto, 1960: vol. II, pp. 37-52.

13. Para los participantes en el ritual de la Apertura de la Boca, ver Otto, 1960: vol. II 16-26. Para los utensilios empleados, Otto, 1960: 10-16 y Roth, 1992 y 1993.

14. Otto, 1960: vol. II, 73-80. Ver también, Otto, 1950.

15. Assmann, 2003b: 462 y 472 y ss.

16. Un buen paralelo encontramos en la tumba ramésida de Nebsumenu (TT 183), donde estas escenas aparecen también en una posición especial, marcando asimismo un acceso o lugar de tránsito dentro de la estructura arquitectónica de la tumba (Assmann, 2003a: 57 y 59).

17. Se trata de un episodio aún no suficientemente aclarado, que algunos han tratado recientemente de poner en relación con el tekenu, un curioso personaje que aparece con frecuencia en la procesión funeraria y cuyo papel y función aún no han sido suficientemente aclarados (Helck, 1986; Reeder, 1994; Menendez, 2005). 


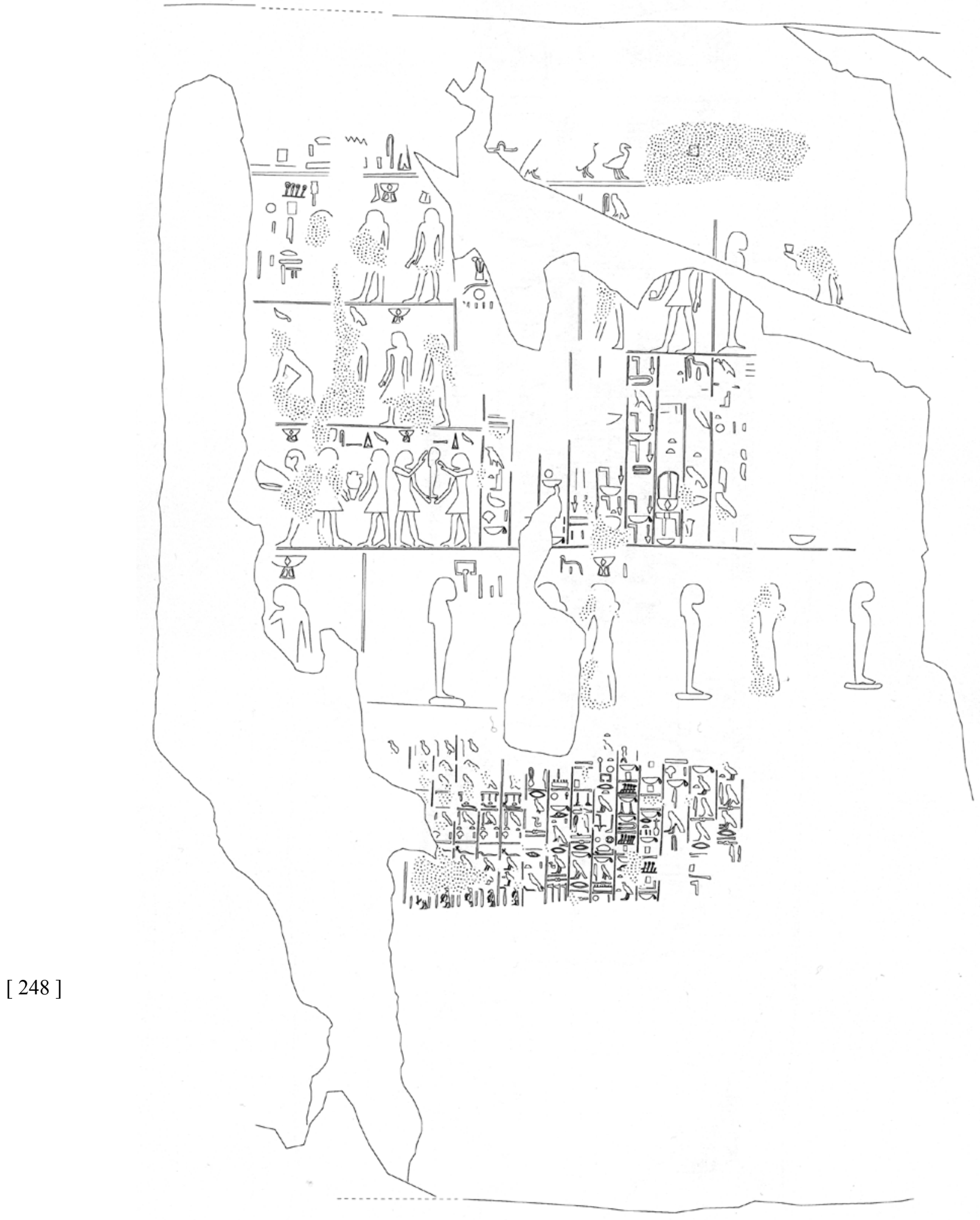

Figura 2. Escenas 4 a 25 y 45 a 47 
grecolatina, ve la "estatua en la piedra" (en la madera, o en cualquiera caso en la materia prima a partir de la cual se va a elaborar). Acto seguido, dedica recomendaciones y exhortaciones a los artesanos que se supone están confeccionando y acabando la imagen del difunto, cuidando de que realicen adecuadamente su labor, a la par que evita, de forma mágica, que el difunto reciba daños en su imagen durante estas, por otra parte, agresivas manipulaciones ${ }^{18}$. Como puede verse, todo parece sacado de un ritual relativo a la estatua, con el objetivo último quizás de purificarla y consagrarla adecuadamente, dándole en definitiva la vida. Una estatua que, en efecto, es el objeto de la Apertura de la Boca en la tumba de Rejmira. Pero recordemos que la TT 11 presenta una de las más antiguas versiones, como más adelante veremos, en la que el ritual se ejecuta no ya sobre la estatua, sino sobre la momia del difunto. Posiblemente sea por esta razón por lo que se considera inconveniente o incongruente incluir aquí las Escenas 8-21.

Lo importante es que, si esto es así, entonces se nos antoja que habría que prestar más atención a la hipótesis de P. Barthelmess, que, contra la opinión de Otto, considera que, al menos en estos primeros momentos en los que se representan el ritual in extenso (Dinastía XVIII), se hace una distinción entre lo que es la Apertura de la Boca según se haga en una estatua (el caso paradigmático de Rejmira) o sobre la momia (sería el caso de Djehuty) ${ }^{19}$. Sirva esto como una primera muestra de las aportaciones de carácter general, para una mejor comprensión del ritual en su complejidad, que pueden extraerse del estudio concreto de la versión presente en TT 11.

B) Pasemos ahora al registro inferior. Aquí encontramos reunidas una docena de escenas, claramente agrupadas como los actos últimos de la liturgia. Tras una nueva serie de purificaciones de la momia a base de agua e incienso, como viene siendo habitual (Escenas 47 a 55) ${ }^{20}$, se llega a la representación de la ofrenda de alimentos propiamente dicha (Escenas 69 y 70). A juzgar por el amplio desarrollo iconográfico que recibe, y por el lugar que ocupa, justo por encima de una larga y detallada lista de ofrendas (o "menú"), no cabe duda de que se entiende como un momento de especial relevancia, un objetivo y fin en sí mismo hacia el que está abocado todo el conjunto del ritual de la Apertura de la Boca.

Finalmente, encontramos otra imagen que tampoco aparece con frecuencia en las diferentes copias del ritual y que parece ser asimismo objeto de un énfasis particular: el traslado de la imagen en unas andas por los "Nueve Amigos" y su instalación en un naos, capilla o sagrario, llamado "La (capilla) Blanca", donde queda depositada, todo ya concluido. Se trata claramente de un elemento extraído de la liturgia cotidiana de los templos, de la veneración a las imágenes depositadas en los santuarios a lo largo y ancho del país egipcio, que es una de las fuentes de las que bebe el ritual de la Apertura de la Boca, cuyos orígenes y composición son, como vemos, francamente complejos. Son las Escenas 73 y 74, que recogen actos considerados finales ${ }^{21}$.

18. Otto, 1960: vol. II, 52-73.

19. Para esta divergencia interpretativa, ver Otto, 1960: vol II, 29; Barthelmess, 1992: 93-100. Se trata de una cuestión que merece un estudio más profundo, cotejando diferentes versiones de la Apertura de la Boca con atención preferente a si el ritual es realizado sobre una estatua o sobre la momia propiamente dicha del difunto, estudio que por el momento no se ha hecho.

20. Estas escenas, situadas en la pared derecha del panel, han sufrido muchas mutilaciones, pero para nuestra fortuna han sido de las más beneficiadas por la recuperación de fragmentos expoliados en las excavaciones del exterior.

21. Cf. Otto, 1960: vol. II, 164-170. Un buen paralelo de esta escena se conserva en la TT 48 (Amenemhet-Surer); cf. Säve-Söderbergh, 1957: 43-44 y pl. XLVII. 


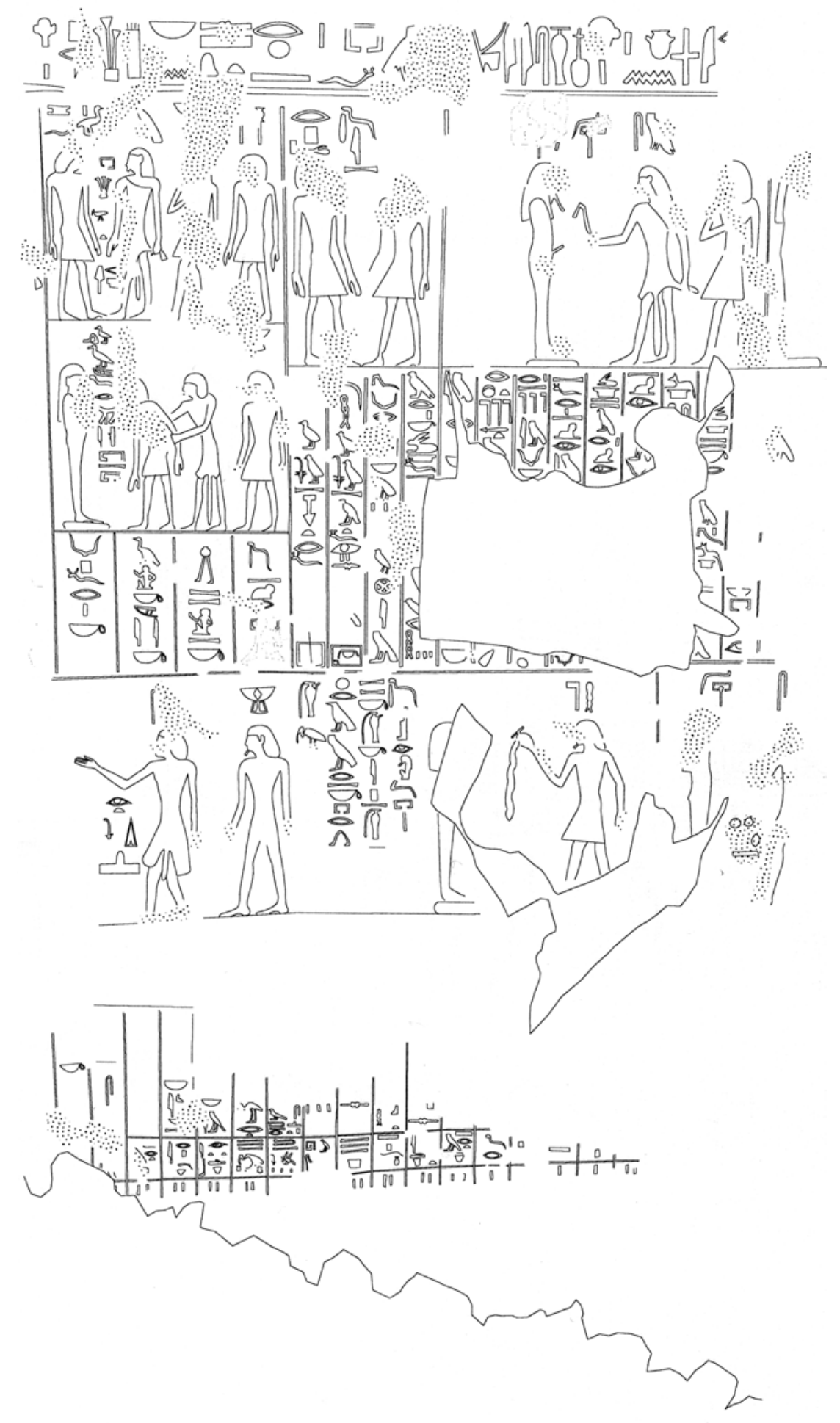

Figura 3. Escenas 25 a 31 y 69 


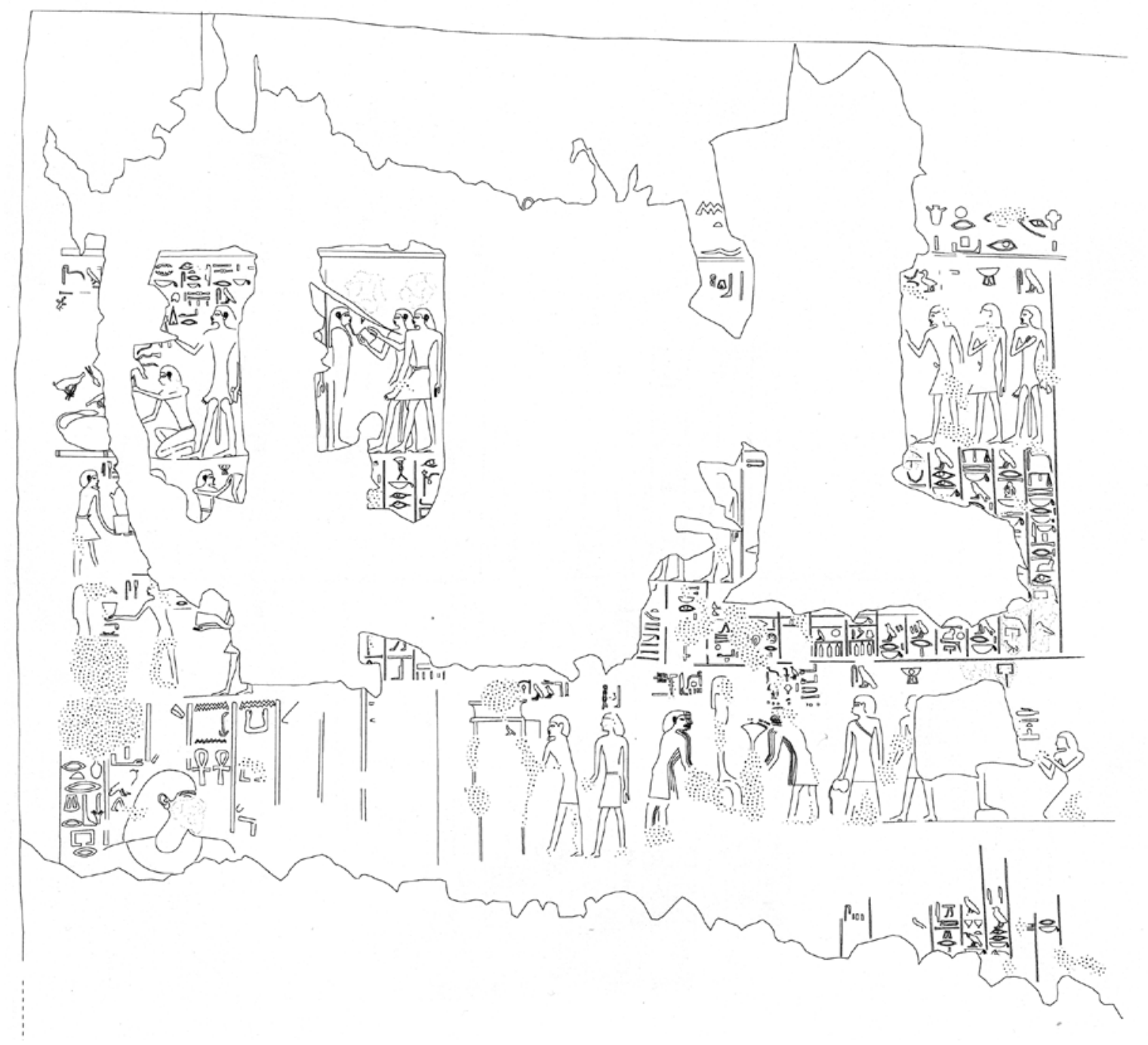

Figura 4. Escenas 32 a 44 y 69 a 74

Resulta muy significativo el hecho de que estas últimas viñetas y textos de la Apertura de la Boca en la TT 11 desemboquen en una gran representación del difunto bienaventurado, Djehuty, sentado delante de una mesa de ofrendas bien abastecida, hacia la que alarga la mano, en actitud de tomar las piezas selectas que se le presentan. Justo detrás de la citada mesa, aparece la gran lista de ofrendas a la que aludíamos más arriba, por desgracia aún medio enterrada por los escombros que provienen de la capilla. El mensaje, a nuestro modo de ver, está claro: tras realizarse sobre la momia el complejo y sofisticado ritual de la Apertura de la Boca, el difunto no solo queda preparado para una vida eterna feliz y bienaventurada, sino que también recupera la plena capacidad para nutrirse de los alimentos y de las ofrendas correspondientes de su culto funerario, que a la postre darán poder y fuerza a su espíritu para el eterno viaje por el Más Allá. 


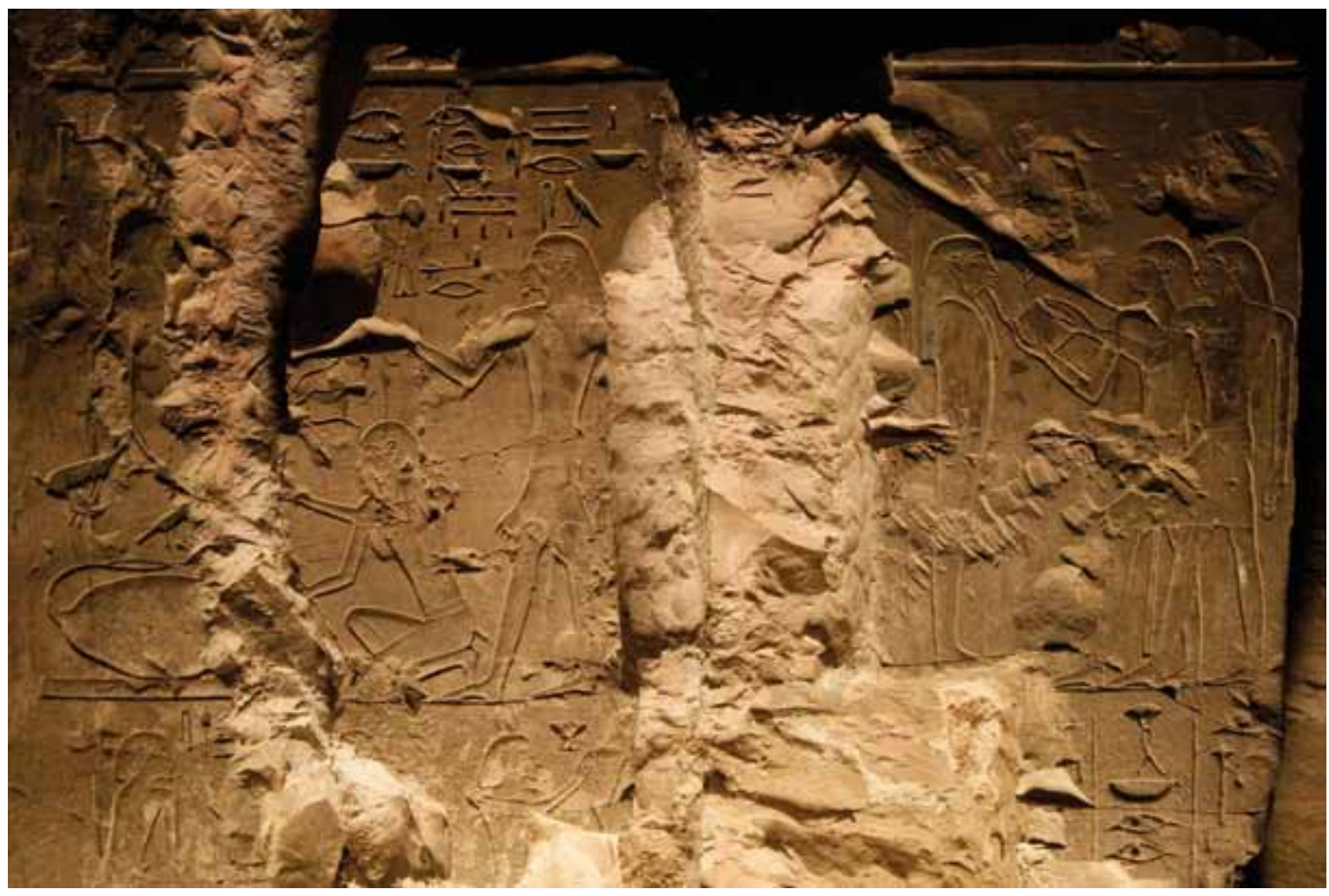

Figura 5. Escenas 36 y 43

\section{Conclusiones}

Es hora de ir perfilando algunas conclusiones o valoraciones de tipo general. Como creemos que ha quedado bien patente, el estudio concreto del ritual de la Apertura de la Boca en la tumba de Djehuty permite al menos apuntar que la selección y la distribución de escenas, dentro de un ámbito iconográfico concreto (una tumba en este caso), no debe entenderse como una simple copia de un modelo canónico original, ni tampoco el resultado de una elección aleatoria. Por el contrario, debe responder a una lógica y a una coherencia interna, dependiente de determinados conceptos religiosos funerarios, así como de una interpretación sagrada y ri- tual de los espacios que constituyen la tumba. En especial nos resultan pertinentes las propuestas de J. Assmann, según el cual habría que abandonar la idea de reconstruir un supuesto modelo completo original de la Apertura de la $\mathrm{Boca}^{22}$, que se entendería como la piedra de toque para estudiar -y comprendertodas las copias que se nos han conservado. Por el contrario, el camino correcto pasaría por la valoración individualizada de las diferentes versiones o elaboraciones que tenemos, cada una de ellas en su contexto histórico y cronológico propio, cada una de ellas en función de unas necesidades, posibilidades o limitaciones derivadas en buena medida, como dijimos más arriba, del concepto de la tumba en que se incluye y de los espacios que la componen ${ }^{23}$. 


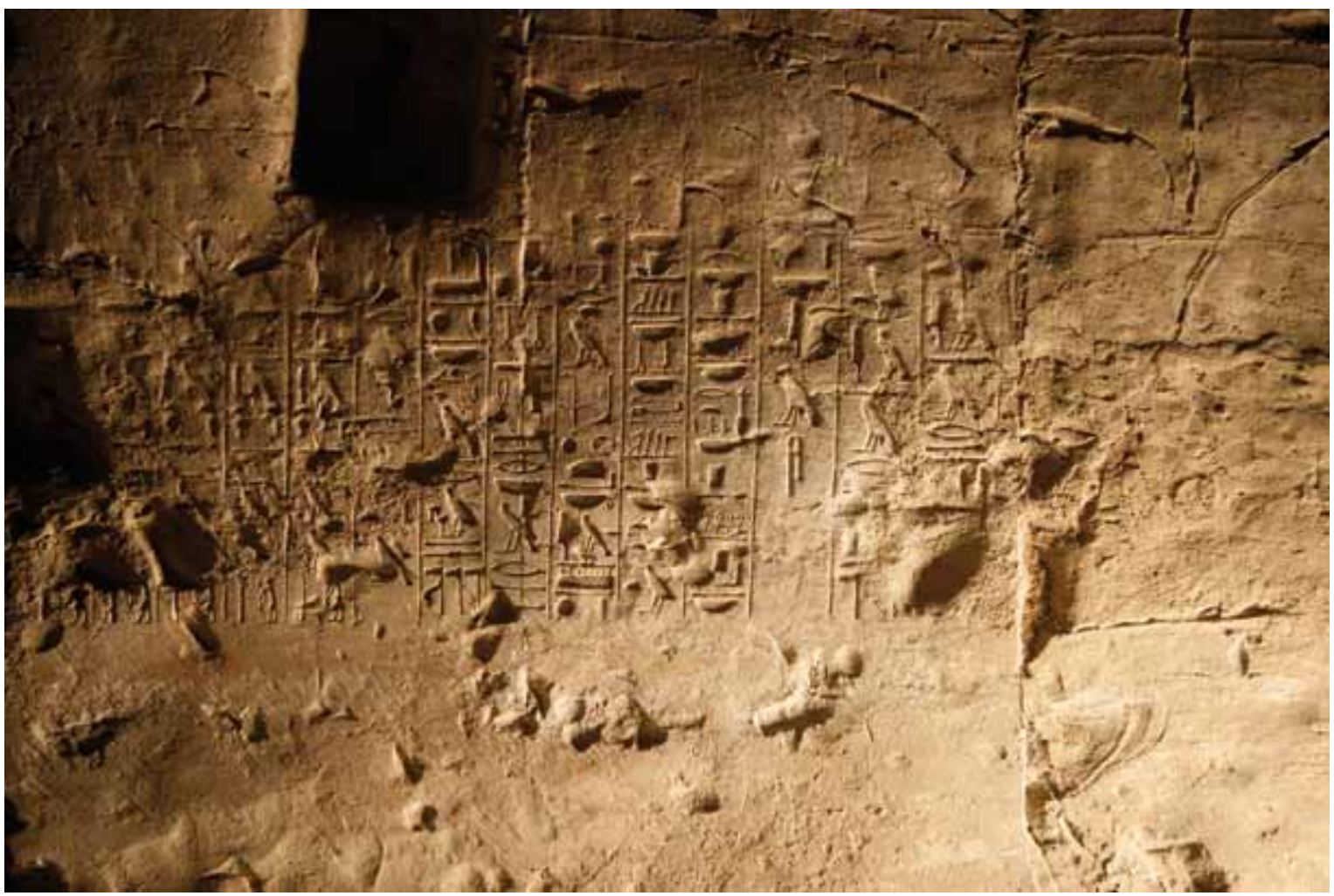

Figura 6. Texto Escenas 50 y 57

Aquí, sin duda, el estudio de la tumba de Djehuty se nos antoja francamente prometedor, y con toda probabilidad conllevará notables aportaciones. En primer lugar, y se trata de un dato a nuestro modo de ver de gran importancia, porque pocas tumbas han dejado un desarrollo tan amplio y completo del ritual de la Apertura de la Boca. Tenemos identificadas y numeradas, provisionalmente, más de treinta escenas o secuencias ${ }^{24}$, y en su momento debió de comprender en torno a unas cuarenta, o quizás más. Recordemos que la tumba que sirve de paradigma y modelo, la TT 100, de Rejmira, presenta alrededor de cincuenta escenas, de las 75 que idealmente Otto adscribía a la liturgia canónica "completa" 25 . Esto es de por sí algo excepcional, ya que, como señala el propio Otto, en contadas ocasiones las versiones contienen más de seis o siete $^{26}$. Además, en la TT 11 la mayoría van acompañadas de textos relativamente largos, que convierten a esta pared casi en una obra literaria, de gran interés y riqueza. Esto, dicho sea de paso, contrasta también con la tónica habitual en las tumbas tebanas, que hace que las secuencias de la Apertura de la Boca vayan normalmente acompañadas solo por epígrafes generales o incluso despojadas por completo del texto correspondiente. Así, y por referirnos solo a tumbas más o menos contemporáneas de la TT 11, de la Dinastía XVIII,

24. Ver Apéndice, al final.

25. Una cifra que en realidad constituye una enumeración artificial, pues muchas escenas que Otto considera independientes son en realidad repeticiones o duplicados de un mismo acto o momento litúrgico (Assmann, 2003a: 55; Assmann, 2003b: 457). El propio Otto destaca lo raro que es encontrar una versión de la Apertura de la Boca que incluya más allá de siete u ocho escenas (1960: vol. II, 28).

26. Otto, 1960: vol. II, 28. 


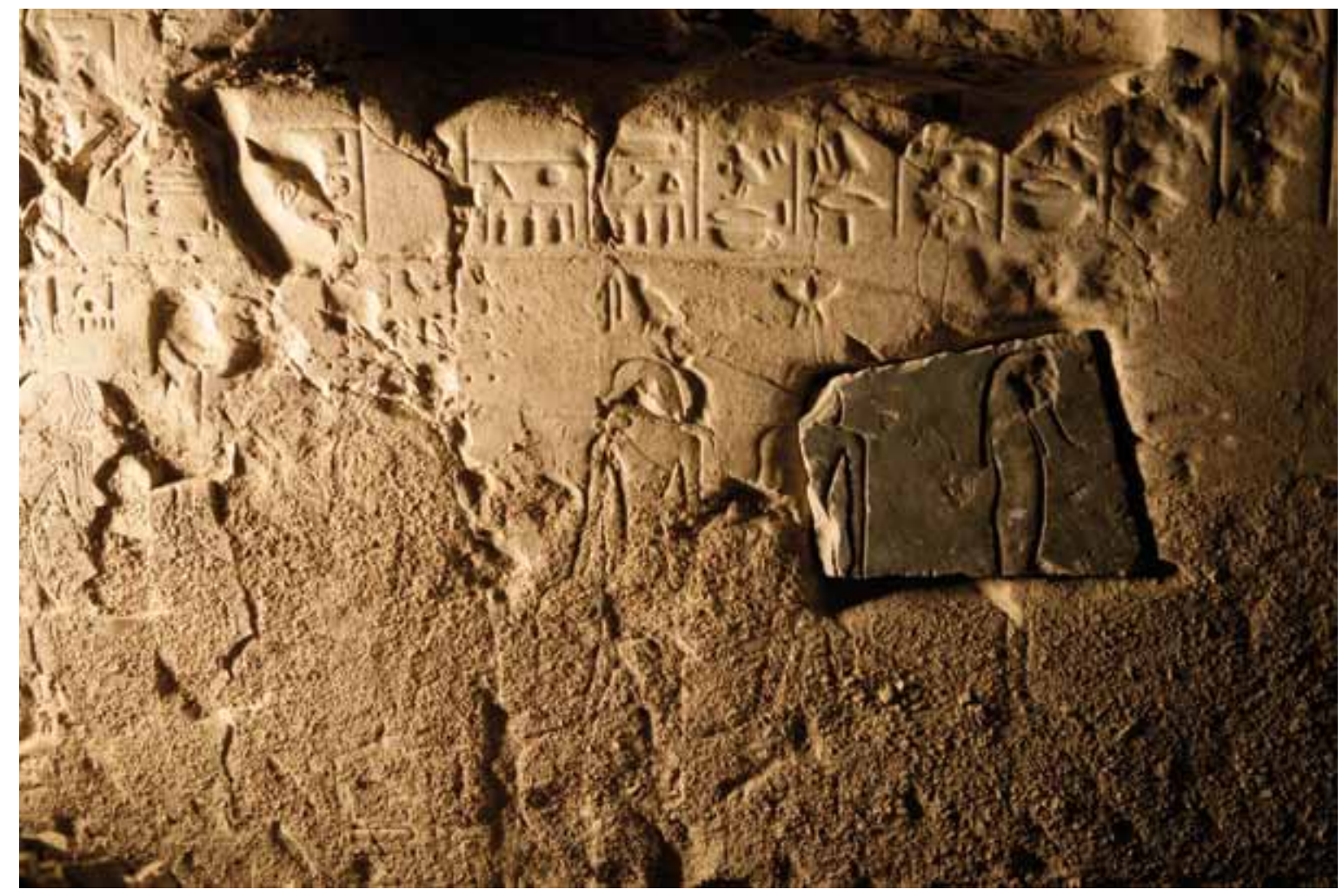

Figura 7. Estado de la pared, con reposición actual de un fragmento

la época más esplendida y fecunda en cuanto a representaciones de este ritual, señalemos que la TT 81, de Ineni, solo presenta una selección de 10 escenas, en las jambas del acceso al pasillo ${ }^{27}$, aproximadamente las mismas que también encontramos en la tumba de Menna (TT 69) ${ }^{28}$. En el primer caso las imágenes aparecen acompañadas tan solo con un breve epígrafe, mientras que en la TT 69 ningún texto ha sido incluido. En la tumba de Senemiaj
(TT 127) son $16^{29}$, mientras que en otras apenas se incluyen cuatro o cinco, como sucede en la TT 56, de Userhat ${ }^{30}$. En la tumba de Nebamon (TT 17) el desarrollo es más amplio: aparecen unas 25 escenas, pero todas ellas están tratadas con una gran sencillez compositiva, repitiendo invariablemente el mismo modelo, con sólo un oficiante delante de la momia; aquí, de nuevo, solo un breve epígrafe de texto acompaña cada secuencia ${ }^{31}$.

27. Dziobek, 1992: 65 y ss., y pls. 19 b y 54.

28. Hodel-Hoenes, 2000: 109-110.

29. Según inspección visual del autor, gracias la visita del equipo del Proyecto Djehuty en la Campaña 2006. Esta tumba, muy bien conservada y restaurada, quedó en proyecto de publicación por Th. Säve-Söderbergh en su serie Private Tombs at Thebes (cf. Porter-Moss, vol. I-1 (2 ${ }^{\mathrm{a}} \mathrm{ed}$.): 241-3).

30. Hodel-Hoenes, 2000: 76-77.

31. Säve-Söderbergh, 1957: 31, y pl. XXVI. Será interesante comparar la TT 11 con la TT 183, con casi 40 escenas con sus textos correspondientes, pero hay que tener presenta que la TT 183, de Nebsumenu, es de época Ramésida, y que constituye un caso excepcional, que contrasta con la práctica de presentar la Apertura de la Boca en una sola imagen que sintetiza diferentes fases del ritual, práctica que se impone con toda claridad a partir de inicios de la dinastía XIX (cf. Barthelmess, 1992: 93 y ss.; Assmann, 2003a). 
Por otra parte, y por si fuera poco lo anteriormente resaltado, la representación del Ritual de la Apertura de la Boca en la TT 11 es una de las más antiguas versiones que se nos han conservado-si no posiblemente la primera- de la Dinastía XVIII, lo que la convierte en un objeto de estudio inestimable para analizar la incorporación de esta liturgia al panorama iconográfico y textual de las tumbas del Reino $\mathrm{Nuevo}^{32}$. Dejando de un lado los mausoleos de determinados notables, contemporáneos como Djehuty de Hatshepsut, cual es el caso, por ejemplo, de Duauy-nejej (TT 125) ${ }^{33}$ o de Ahmose-Humay (TT 224) -ninguna de las dos publicadas adecuadamente-, la única versión que, hasta donde podemos conocer, podría ser más temprana que la de Djehuty, sería la de la TT 21, de User, mayordomo que fue de Tutmosis I. Sin embargo en la actualidad sabemos que la decoración de esta tumba, que como en otros tantos casos quedó sin terminar, ha de datarse en el reinado de Tutmosis II o incluso de la propia Hatshepsut ${ }^{34}$, lo que asimismo la convertiría casi en contemporánea de Djehuty. Además, en la TT 21 solo queda un pequeño fragmento que representa, también de manera muy escueta y con un breve texto, dos escenas del ritual ${ }^{35}$. En el caso de la TT 11, disponer de una versión tan amplia, tan bien ilustrada en sus imágenes y enriquecida con textos largos y cuidados, y que además resulta ser de las pioneras cronológicamente hablando, dice mucho del valor que podrá tener para conocer mejor la Apertura de la Boca y su papel en los usos y costumbre funerarios egipcios.

32. Otto deja bien claro que solo a partir del Reino Nuevo contamos con versiones explícitas y desarrolladas del ritual, y que posiblemente en el reinado de Amenhotep I se instaura esta práctica (1960: Vol. II, 8).

33. Esta tumba se suponía que también iba a ser publicada por Th. Säve-Söderbergh ( $c f$. Porter-Moss I -1 (2 ed.): 237 y ss).

34. Davies, 1913: 27.

35. Davies, 1913: pl. XX. 
Apendice

Relación de escenas de la apertura de la boca conservadas en la TT $11^{36}$

Registro superior (de derecha a izquierda)

Escena 1: Enunciado general

(Escenas 2 y 3)

Escena 4: Purificación con natrón del Alto Egipto

Escena 5: Purificación con natrón del Bajo Egipto

Escena 6: Purificación con incienso

Escena 7: Segunda purificación con incienso

Escena 9: Introducción del sacerdote sem

Escena 11/19: Desvestir al sacerdote sem

Escena 23. Sacrificio del bóvido

Escena 24: Ofrenda de la pata y corazón del bóvido

Escena 25: Presentación de la pata

Escena 26: Apertura de la Boca con la herramienta ntrty

Escena 27: Apertura de la Boca con la herramienta $w r-h k 3 w$

Escena 28: Presentación de la imagen ante el $r p$ 't

Escena 31: Introducción del "Hijo, su amado"

Escena 32: Apertura de la Boca con la herramienta $m \underline{d} d f t$ y con el dedo de oro
Escena 33: Apertura de la Boca con el dedo meñique

Escena 34: Presentación del $\mathrm{nms}$

Escena 41: Presentación de la vasija de agua

(Escena 42)

Escena 36: Presentación de los ' $b t$

Escena 43: Segundo sacrificio del bóvido

Escena 44: Segunda ofrenda de la pata y

del corazón del bóvido

Registro inferior (de derecha a izquierda)

(Escena 46)

Escena 47: Purificación con incienso

Escena 48: Presentación del $\mathrm{nms}$

Escena 50: Presentación del sšmt

Escena 55A: Conjuro del ungüento

Escena 57: Presentación del cetro y la maza

Escena 69: Libación

Escena 69/70: La ofrenda

Escena 73: Traslado por los "nueve compañeros"

Escena 74: La imagen en la capilla 


\section{Bibliografía}

Assmann, J.

2003a The Ramesside tomb of Nebsumenu (TT 183) and the ritual of Opening the Mouth, en Strudwick, N.; Taylor, J. H. (eds.): The Theban Necropolis: Past, present and future, Cambridge: 53-60.

2003b Mort et au-delà dans l'Égypte ancienne. Paris.

BALY, T. J. C.

1930 Notes on the ritual of Opening the Mouth, JEA XVI: 173-186.

BARTHELMESS, P.

1992 Der Übergang ins Jenseits in den thebanischen Beamtengräbern der Ramessidenzeit. Heidelberg.

DAVIES, N. DE G.

1913 Five Theban Tombs. London.

Diego Provencio, A. DE

2003 Autobiografía de Djehuty: La "Estela de Northampton", BAEDE 13: 117 y ss.

DZIobeK, E.

1992 Das Grab des Ineni. Theben Nr. 81. Mainz.

ENGELMANN-VON CARNAP, B.

1999 Die Struktur des Thebanischen Beamtenfriedhofs in der ersten Hälfte der 18. Dynastie. Berlin.

FISCHER-ELFERT, H. W.

1998 Die Vision von der Statue im Stein. Studien zum altägyptischen Mundöffnungsritual. Heidelberg.

GALÁN, J. M.

2006 En busca de Djehuty: crónica de una excavación arqueológica en Luxor. Barcelona.

HeLCK, W.

1986 s.u. "tekenu”, LÄ, VI: 309-309.
Hodel-Hoenes, S.

2000 Life and Death in Ancient Egypt: Scenes from private Tombs in New Kingdom Thebes. Cornell.

MenÉndez, G.

$2005 \mathrm{La}$ procesión funeraria de la tumba de Hery (TT 12) en Dra Abu el-Naga, $B A E D E$ 15: 44-55.

Northampton, Marquis of; Spiegelberg, W.; Newberry, P. E.

1898-1899 Report on some excavations in the Theban Necropolis during the winter of 1898-1899. London.

Отто, Е.

1950 An ancient Egypti an hunting ritual, JNES 9: 164-177.

1960 Das Ägyptische Mundöffnungsritual. Wiesbaden, 2 vols.

ReEDER, W G.

1994 A rite of passage: The enigmatic Teke$\mathrm{nu}$ in ancient egyptian funerary ritual, KMT 5 (3): 53-59

Roth, A. M.

1992 The $p s \check{s}-k f$ and the "Opening of the Mouth" ceremony: a ritual of birth and rebirth, JEA 78: 113-147.

1993 Fingers, stars, and the "Opening of the Mouth": the nature and functions of the ntrwy-blades, JEA 79: 57-79.

SÄVE-SöDERBERGH, TH.

1957 Four Eighteenth Dynasty tombs. Oxford.

Schulman, A. R.

1984 The iconographic theme "Opening of the Mouth" on stelae, JARCE XXI: 169196. 


\section{Trabajos de Egiptología Papers on Ancient Egypt}

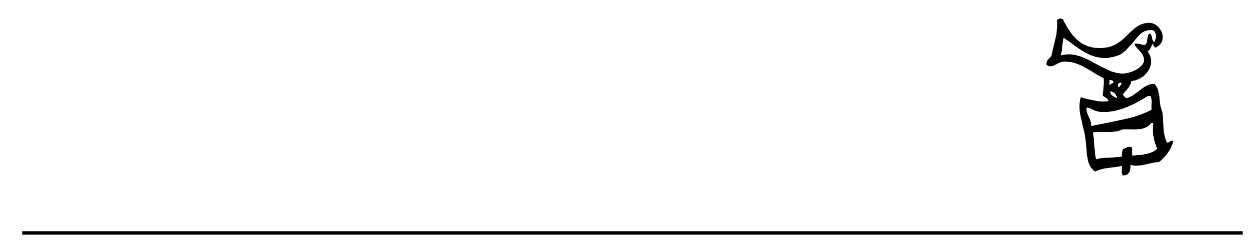

Número 5/2 2009 


\section{Actas \\ III Congreso Ibérico de Egiptología III Congresso Ibérico de Egiptologia}

Editores

Miguel Ángel Molinero Polo Covadonga Sevilla Cueva 


\title{
Editor
}

Miguel Ángel Molinero Polo

Universidad de La Laguna

\section{Consejo Editorial}

\author{
Antonio Pérez Largacha \\ Universidad de Castilla-La Mancha \\ José-R. Pérez-Accino \\ Birkbeck, Universidad de Londres \\ Covadonga Sevilla Cueva \\ Universidad Autónoma de Madrid
}

\section{Comité Científico}

Josep Cervelló i Autuori

Universitat Autònoma de Barcelona

$\mathrm{M}^{\mathrm{a}}$ José lópez Grande

Universidad Autónoma de Madrid

Josep Padró i Parcerisa

Universitat de Barcelona

$\mathrm{M}^{\mathrm{a}}$ Carmen Pérez Die

Museo Arqueológico Nacional, Madrid

Ester Pons Mellado

Museo Arqueológico Nacional, Madrid

José M. Serrano Delgado

Universidad de Sevilla

\section{Colaboradores Editoriales}

Linda Steynor

English editorial assistant

Hervé Mouriacoux

Assistant éditorial pour la langue française 
Trabajos de Egiptología está producida por Isfet. Egiptología e Historia c/ Blanco $1,2^{\circ}$

38400 Puerto de la Cruz

Tenerife-Islas Canarias

España

Maquetación: Proyecto Limón

(C) Autores de los artículos aparecidos

y Consejo Editorial de Trabajos de Egiptología - Papers on ancient Egypt

Depósito Legal: TF-2303-2009

ISSN: $1695-4750$

Imprime: Gráfica Los Majuelos, S.L.L.

imprenta@graficaslosmajuelos.com

Tfno.: 922311455 


\section{Comité Científico \\ III Congreso Ibérico de Egiptología III Congresso Ibérico de Egiptologia}

Miguel Á. Molinero Polo

Universidad de La Laguna

Presidente del Comité Organizador del III Congreso Ibérico de Egiptología

Miembro del Comité Organizador del I Encuentro de Egiptología

Josep Cervelló Autuori

Universitat Autònoma de Barcelona

Presidente del Comité Organizador del II Congreso Ibérico de Egiptologia

José Manuel Galán Allué

Consejo Superior de Investigaciones Cientificas

Director del Proyecto Djehuty, Luxor, Egipto

$\mathrm{M}^{\mathrm{a}}$ Helena Trindade Lopes

Universidad de Lisboa

Directora de la Misión Arqueológica Portuguesa en Menfis

Josep Padró i Parcerisa

Universitat de Barcelona

Director de la Misión Arqueológica de Oxirrinco

Antonio Pérez Largacha

Universidad de Castilla - La Mancha

Miembro del Comité Organizador del I Encuentro de Egiptología

José Ramón Pérez-Accino

Birkbeck College, University of London

Miembro del Comité Organizador del I Encuentro de Egiptología

$\mathrm{M}^{\mathrm{a}}$. Carmen Pérez Díe

Museo Arqueológico Nacional

Directora de la Misión Arqueológica Española en Heracleópolis Magna, Egipto

Covadonga Sevilla Cueva

Universidad Autónoma de Madrid

Miembro del Comité Organizador del I Encuentro de Egiptología 